\title{
EFFECTS OF ANXIETY-RELIEVING DRUGS ON UNIT DISCHARGES IN HIPPOCAMPUS, RETICULAR MID- BRAIN, AND PRE-OPTIC AREA IN THE FREELY MOVING RAT*
}

\author{
M. E. OLDS and J. OLDS \\ Department of Psychology, University of Michigan, Ann Arbor, Michigan
}

(Accepted 15 February 1968)

\begin{abstract}
Summary-The effects on unit discharges of various doses of the compounds chlordiazepoxide, meprobamate, sodium pentobarbital, and diazepam were studied in the unanesthetized, unrestrained rat. Recordings of action potentials were made simultaneously in hippocampus, pre-optic region, and the reticular formation of the midbrain. The doses of chlordiazepoxide were $5,10,20$ and $40 \mathrm{mg} / \mathrm{kg} ; 5,10$ and $20 \mathrm{mg} / \mathrm{kg}$ of sodium pentobarbital; 80,100 and $120 \mathrm{mg} / \mathrm{kg}$ of meprobamate, and finally 5,10 and $20 \mathrm{mg} / \mathrm{kg}$ of diazepam.

In the hippocampus, chlordiazepoxide depressed spontaneous activity at every dose used. The reduction ranged from 30 to $50 \%$, but in no case was there inhibition of all discharges. Diazepam also had substantial depressing effects on the activity in this region of the brain. In contrast, sodium pentobarbital had relatively minor effects in the lower dose range, but significant depressing effects at the higher doses. Meprobamate also had comparatively small effects in the hippocampus.

In the pre-optic area, chlordiazepoxide and meprobamate depressed spontaneous activity at the higher dose range. There were small effects in the lower dose range. Sodjum pentobarbital also had minor depressing effects at all doses. Diazepam caused less depression even at the higher doses than either chlordiazepoxide or meprobamate, and these effects were transient.

In the midbrain reticular formation, meprobamate caused substantial depression of spontaneous activity even at the lower doses. Sodium pentobarbital similarly depressed activity, but the onset of effect was less delayed than with meprobamate. Chlordiazepoxide at low doses caused less depression of reticular midbrain neurons than of hippocampal or pre-optic region ones. At high doses, the effect was similar to that of meprobamate.

The data suggest the possibility of a mode of action of chlordiazepoxide and diazepam which implicates the hippocampus, whereas in the case of sodium pentobarbital and meprobamate, the mode of action appears to implicate the midbrain reticular area. Such a view is based upon comparison of effects at low doses on spontaneous activity of the three regions investigated.
\end{abstract}

CuINICAL studies suggest that chlordiazepoxide may sedate through increasing the wellbeing of the patient rather than depressing him. Studies on animal behavior also report an increase in the animal's willingness to endure punishment to obtain food or water after chlordiazepoxide (Special Report, 1965). This compound may thus be enhancing positive drives rather than reducing anxiety.

There are also reports of facilitatory effects on behavior which suggest a component in the mode of action of this type of compound clearly absent in reports of barbiturate or phenothiazine treatment. For example, decision time in a discriminatory test was reduced

*Supported by PHS grant MH-2839 and Hoffman La Roche. 
after chlordiazepoxide injection in rats (LIBERSON et al., 1963), and there was increased responding in an operant conditioning test with chlordiazepoxide and meprobamate treatment (Richelle et al., 1962; Xhenseval and Richelle, 1965). It has also been reported that diazepam, another benzodiazepine, caused motor hyperactivity followed by a relaxed phase in freely moving cats (HERNÁNDEZ-PÉON et al., 1964). When the effects of chlordiazepoxide, meprobamate and sodium pentobarbital were compared in self-stimulation tests for electrical reward in lateral hypothalamus, the first compound caused large increases in responding at doses comparable to meprobamate and sodium pentobarbital, both of which caused decreases in responding (M. OLDS, 1966). It was thus possible to distinguish between the action of these drugs in regard to each other, and also to implicate the lateral hypothalamus as one possible site of action of chlordiazepoxide.

The vast literature on the effects of these compounds on EEG, evoked responses, seizures, or cortical arousal caused by reticular formation stimulation has been reviewed by KILLAM (1962) and Domino (1962). In general, there is no agreement as to whether the site of action of chlordiazepoxide and meprobamate is similar to that of the barbiturates, or essentially different; the former compounds act primarily on limbic structures, the latter drugs on midbrain ones (KLeTZIN and SwaN, 1959; SchalleK et al., 1964; SCHALleK and KueHN, 1965). At high doses, chlordiazepoxide and meprobamate induce EEG synchrony and depress evoked potentials, just as the barbiturates do (WHITE et al., 1965), and there is little to substantiate the behavioral and clinical reports of enhancement of drives and facilitatory action on behavior. The claim has been made that at low doses meprobamate has significant effects on limbic structures before excitability in the midbrain reticular formation, or before the cortex shows marked changes (KLETZIN and SwaN, 1959). WINFIELD and AivazIAN (1961), Gibbs and GibBs (1962), Roldan and Escobar (1961), Schalleck and KueHn (1965), HERNÁNDEZ-PÉON et al. (1964), and REQUIN et al. (1963) have been reported fast EEG activity both in patients and animals treated with chlordiazepoxide even though behaviorally the subjects showed relaxation. Thus, there are data suggesting that chlordiazepoxide does not primarily act on the structures associated with sleep-wakefulness mechanisms, but on those implicated generally in the modulation of emotional behavior, and that, far from causing sedation as evidenced by EEG synchrony and decreased amplitude of evoked responses from stimulation of the mesencephalic reticular formation, it often causes EEG desynchronization not always associated with motor hyperactivity. In the latter case, action of chlordiazepoxide points to the possible dissociation between effects on EEG recordings and effects on behavior. The data are not conclusive, however, and the view is sometimes held that the mode of action of these anxiety-relieving agents is similar to that of the barbiturates, which also have some facilitatory effects at very low doses (DomINo, 1962). There are no studies which provide direct evidence on this question, not merely because tests and doses are not always comparable, but primarily because the variables investigated give at best indirect evidence of site of activity.

The two reasons behind the studies reported here were: first, to add to the available information on these drugs, by means of quantitative data, using for this purpose discharges from single neurons in areas already implicated both in emotional and sleep-awake mechanisms; and second, to employ the recent techniques of J. OLDS $(1965,1967)$ for recording unitary discharges in the unrestrained animal, as a means of obtaining direct evidence of action in a given structure. This could only be done by means of stable recordings of action potentials for relatively long intervals of time, so that mode of action of pharmacological agents could be determined reliably. With these aims in mind, effects of chlordiazepoxide, 
meprobamate, diazepam, and sodium pentobarbital were compared on freely-moving rats prepared for long periods of unitary discharge recording.

\section{METHODS}

Albino rats, weighing between 300 and $350 \mathrm{~g}$ were used. In general, the surgical and recording methods of units were similar to those described in detail in previous reports (J. OLDS, 1965, 1967). Several fine wire nichrome electrodes, $67 \mu$ in diameter, were implanted in each animal. These probes were enamel insulated at the factory and bared only at the cross section of their tips. They were placed initially by means of stereotaxic guidance (DE GROOT, 1963) into a specific anatomical area, and then moved slightly within that area under neurophysiological guidance until action potentials with signal to noise ratio of at least $3: 1$ appeared. When these responses could be held for at least $20 \mathrm{~min}$ in the anesthetized animal (sodium pentobarbital, $50 \mathrm{mg} / \mathrm{kg}$ i.p.), the electrodes were permanently fixed in place with dental cement. Each rat was prepared with six to eight microelectrodes for the purpose of recording unitary discharges in hippocampus, reticular formation of the midbrain, and pre-optic area (see Fig. 1). A large bare wire, $250 \mu$ in diameter and about $1 \mathrm{~cm}$ in length, was placed in the brain 1 or $1 \frac{1}{2} \mathrm{~cm}$ from any of the microelectrodes on the anterior-posterior axis. All electrodes were attached to a nylon plug, and the animal was given at least 1 week or more for recovery. Earlier work (J. OLDS, 1967; StRUmwasser, 1958) had shown the feasibility of chronic monopolar recordings of extra-cellular action potentials.

Data obtained with these techniques showed that the micro-electrodes remained for weeks in approximately the same position, as floating electrodes. Movement of brain tissue in these areas was probably very small and interfered little with recording. Eventually the locus of the electrode tip was determined histologically after in situ fixation of tissues. Positional check was determined by the frozen section method, Weil and cresyl violet stains (Fig. 1).

Low-noise leads (Microdot cable) were used to make connections between electrodes, pre-amplifiers and amplifiers. A commutator and counter-balanced arm allowed the animal to move freely in a plastic cylinder, $1 \frac{1}{2} \mathrm{ft}$ in diameter, while observation of spontaneous discharges were displayed on a four-beam Tektronix oscilloscope. The plastic cage was housed in a large sound-dampened insulated box, $3 \times 3 \times 3 \mathrm{ft}$. Observation of the animal's behaviour was by means of a small window $2-3$ in. on one of the sides. The test box was lit in order to provide "quiet awake" conditions, since behavioral activity is known to occur in the dark.

A single high-noise wire was attached on one end to the nylon connector making contact with the plug on the animal's head, and to the input socket of an amplifier at the other end. Its noisiness was augmented by leaving it open circuited at the end of the nylon connector. Its amplified signal indicated movements of the animal; this was photographed with the data. Samples of neural activity in which movement occurred were rejected.

Recording of the traces (three or four discharges simultaneously from each animal displayed on multi-beam oscilloscope) was done by photography with a Grass C-4 camera, at $500 \mathrm{~mm} / \mathrm{sec}$ on moving $35 \mathrm{~mm}$ linagraph paper (Kodak KIND 1732).

All drug experiments were carried out on intact rats, unrestrained, used to the test chamber. 
During an experiment, the discharges from at least one neuron, but often more, in each of the three locations, pre-optic area, midbrain reticular formation, and hippocampus, were monitored throughout the test period. All the spikes above noise level (two and three times the amplitude of noise) were counted during a $200 \mathrm{msec}$ time interval. Presumably the basic data consisted of spikes from the same neuron-if it fired two or more times during a $200 \mathrm{msec}$ period-and spikes of other neurons, when of different amplitude. There were several periods of recording during the $180 \mathrm{~min}$ of the test, of which the first $90 \mathrm{~min}$ were given to determination of spontaneous activity before drug injection, and the other $90 \mathrm{~min}$ for determination of drug effects. Subjects were selected for tests when unit responses had been kept for a minimum of 8 days after surgery, often longer, and ratios of responses to noise were such as to allow counting, on the basis of spike amplitude, of discharges during $200 \mathrm{msec}$ sampling intervals throughout the $180 \mathrm{~min}$ experimental session.

A given test consisted of photographing samples of spontaneous discharges, each sample separated from the next one by $10 \mathrm{sec}$. Eight such samples were taken at each sampling time, 90, 60, 30,15 and $1 \mathrm{~min}$ before injection and 5, 15,30,60 and $90 \mathrm{~min}$ after injection.

At each sampling time, eight different samples of approximately $500 \mathrm{msec}$ each were available for analysis. Of these, the first three without movement artefacts were selected for counting of action potentials during a $200 \mathrm{msec}$ interval. Only those spikes which were clearly demarcated from noise levels by being at least twice or more the height of noise were counted.

For each rat, a mean number of spikes obtained from fifteen separate time samples, each $200 \mathrm{msec}$ long, during the various periods before injection, constituted the "control" values against which values obtained after injection were compared. Test values were obtained also from $200 \mathrm{msec}$ samples of spontaneous firing, at 15, 30,60 and $90 \mathrm{~min}$ following medication. These values were stated as percentages of the control values. A mean value for all animals with electrodes in a given area receiving the same medication was computed for the periods 15, 30, 60 and 90 min after injection. Although the control data was summed over a $90 \mathrm{~min}$ period before injection, whereas the test data was broken down into different intervals after injection, it was possible to compare progressive changes with time of control data by comparing values following injection of saline and glycol with test values following chlordiazepoxide and the other compounds. Progressive changes of spontaneous activity over time were thus the control values for progressive changes of activity, after injection of test compounds. Changes in number of spikes for the period, 15-90 min after injection, were stated as a percent of the control value for each rat and for each group with electrodes in a similar region of the brain.

Effects of drugs during the 15-90 min period after injection, in each area, were compared both with pre-injection control values and with values obtaincd after physiological saline or polyethylene glycol 400 injections, depending on the solvent used. The Mann-Whitney U Test (SIEGEL, 1956) was used for statistical analysis of data to determine effects of the same drug at different doses in the same region, or the same drug at the same dose in different regions.

The drugs used were chlordiazepoxide hydrochloride, at doses of $5,10,20$ and $40 \mathrm{mg} / \mathrm{kg}$; sodium pentobarbital, doses of 5,10 and $20 \mathrm{mg} / \mathrm{kg}$; meprobamate, 80,100 and $120 \mathrm{mg} / \mathrm{kg}$; diazepam 5,10 and $20 \mathrm{mg} / \mathrm{kg}$. All drugs were dissolved either in saline solution or in a polethylene glycol 400 suspension immediately before use and were in all cases injected intraperitoneally. The concentration of each drug was such that the subjects received an 


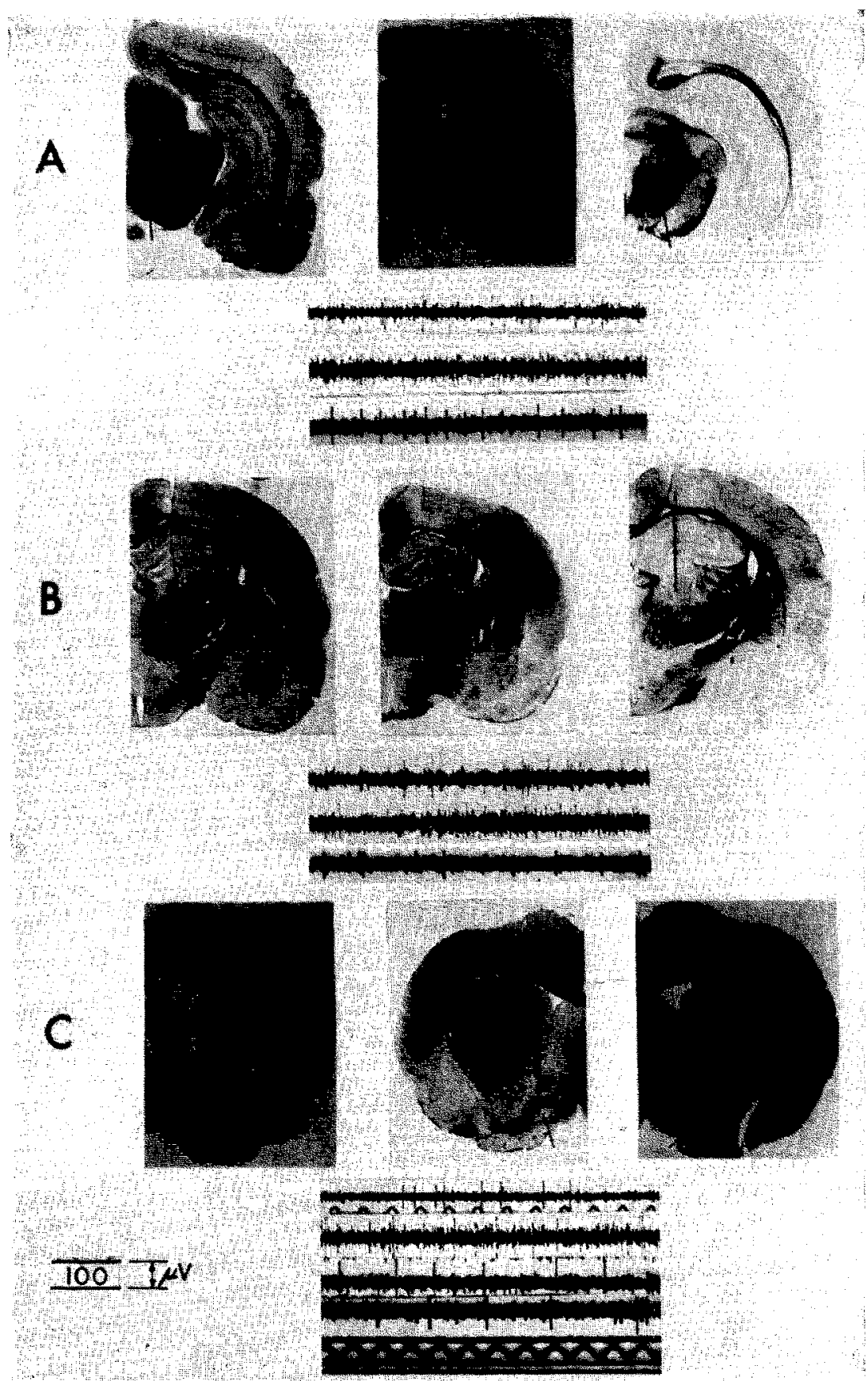

FIc. 1. Transwerse sections, $50 \mu$ thick, Weil stain, showing three typical samples of each brain region from which action potentials were recorded. Panel A: Recording loci in three different subjects-electrodes stereotaxically guided to be in the reticular formation of the midbrain. Below thistological material are sample recordings of spontaneous activity before medication in this region of the brain. Panel B: Loci of electrodes in hippocampus and typical records of activity at such points. Panel $\mathrm{C}$ : Loci of electrodes in the premoptic area and records of spontaneous activity below, Calbration, $100 \mu \mathrm{V}$; abcissa, activity during $100 \mathrm{msec}$; microelectrode tip negative downward. Difference among units are in terms of voltage differences, yielding small deffections in some cases, nther times being of considerable voliage 
equal volume per $\mathrm{kg}$ of body weight. If subjects were used more than once, at least 2 weeks intervened between administration of a drug. Control animals received physiological saline or glycol injections.

\section{Effects in hippocampus}

\section{RESULTS}

Every dose of chlordiazepoxide depressed the spontaneous activity of hippocampal neurons (Table 1). Even at the lowest dose, $5 \mathrm{mg} / \mathrm{kg}$, the mean rate of discharge during the 15-90 min after injection was reduced by $30 \%$ compared to rates before injection. At high doses, firing was reduced by $50 \%$ or more. There were no cases of total inhibition, even at a dose of $40 \mathrm{mg} / \mathrm{kg}$. In seven of the ten subjects (in which spontaneous activity of one or more neurons was monitored during a $90 \mathrm{~min}$ period before injection), a dose of $5 \mathrm{mg} / \mathrm{kg}$ of chlordiazepoxide inhibited discharge of hippocampal neurons. At a dose of $10 \mathrm{mg} / \mathrm{kg}$, all of the ten subjects tested showed significant reduced activity of hippocampal neurons. At a dose of $20 \mathrm{mg} / \mathrm{kg}$, twelve out of twelve subjects were inhibited; and finally, at a dose of $40 \mathrm{mg} / \mathrm{kg}$, seven subjects were inhibited and one showed no change. In all such cases, the subjects were awake and appeared relaxed during the $90 \mathrm{~min}$ test period after injection.

TAble 1. EfFects of Chlordiazepoxide, SOdium Pentobarbital, MeProbamate, and diazepam ON SPONTANEOUS FIRING OF NEURONS IN HIPPOCAMPUS

\begin{tabular}{|c|c|c|c|c|c|c|c|c|}
\hline \multirow[b]{2}{*}{ Drug } & \multirow{2}{*}{$\begin{array}{c}\text { Dose } \\
(\mathrm{mg} / \mathrm{kg})\end{array}$} & \multirow[b]{2}{*}{$N$} & \multicolumn{4}{|c|}{ Mean percentage at time $(\mathrm{min})$ after injection } & \multirow{2}{*}{$\begin{array}{c}\text { Mean } \\
(15-90)\end{array}$} & \multirow{2}{*}{$\begin{array}{l}\text { S.D. } \\
( \pm)\end{array}$} \\
\hline & & & 15 & 30 & 60 & 90 & & \\
\hline \multirow[t]{4}{*}{ Chlordiazepoxide } & le 5 & 10 & 69 & 82 & 66 & 85 & 76 & 26 \\
\hline & 10 & 10 & 64 & 73 & 66 & 59 & $64^{*}$ & 22 \\
\hline & 20 & 12 & 56 & 38 & 50 & 53 & $49 \dagger$ & 16 \\
\hline & 40 & 8 & 71 & 42 & 55 & 70 & $60^{*}$ & 20 \\
\hline \multirow[t]{3}{*}{ Na pentobarbital } & 5 & 5 & 81 & 97 & 68 & 82 & 82 & 27 \\
\hline & 10 & 7 & 86 & 85 & 95 & 78 & 86 & 28 \\
\hline & 20 & 6 & 110 & 98 & 86 & 73 & 91 & 31 \\
\hline \multirow[t]{3}{*}{ Meprobamate } & 80 & 5 & 100 & 101 & 94 & 54 & 88 & 15 \\
\hline & 100 & 5 & 74 & 49 & 81 & 75 & $70^{*}$ & 23 \\
\hline & 120 & 6 & 104 & 99 & 86 & 98 & 97 & 36 \\
\hline \multirow[t]{3}{*}{ Diazepam } & 5 & 5 & 72 & 60 & 62 & 45 & $60 \dagger$ & 20 \\
\hline & 10 & 5 & 49 & 30 & 56 & 44 & $45 \dagger$ & 10 \\
\hline & 20 & 8 & 59 & 57 & 52 & 37 & $51 \dagger$ & 17 \\
\hline \multicolumn{2}{|l|}{ Glycol } & 7 & 118 & 103 & 110 & 106 & 109 & 37 \\
\hline $\mathrm{NaCl}$ & $9 \%$ & 9 & 90 & 89 & 116 & 79 & 94 & 31 \\
\hline
\end{tabular}

* $P=0.05$ Mann-Whitney U Test, Siegel (1956).

† $P=0.01$ between scores obtained after appropriate solvent injection and after administration of test drug. Each score was obtained by calculating the mean number of spikes in three $200 \mathrm{msec}$ periods, at various intervals after drug administration. Results reported as percentages of control values (see text).

Diazepam also depressed neural firing in this region (Table 1). Although this effect was somewhat more variable than was the case with chlordiazepoxide, there was almost $50 \%$ reduction in neuron firing after injection. Here also, as was the case with chlordiazepoxide, 
the depression was not total. At every dose used, a majority of the subjects reduced hippocampal activity; there were no cases of facilitation despite the fact that in the case of diazepam the solvent was polyethylene glycol which invariably, when injected by itself, slightly increased neuron discharge and induced behavioral restlessness (Table 1).

Sodium pentobarbital had comparatively minor effects on the spontaneous activity of these cells. Mean rates of firing during the total test period (Table 3, column 15-90 min) were reduced by $10-20 \%$ after sodium pentobarbital; in the case of chlordiazepoxide and diazepam, the reductions were between 40 and $50 \%$ at high doses.

Furthermore, whereas all hippocampal neurons showed depression after injection of chlordiazepoxide and diazepam, after sodium pentobarbital at a dose of $5 \mathrm{mg} / \mathrm{kg}$, only three out of five cases showed a decrease in activity of these cells; after a dose of $10 \mathrm{mg} / \mathrm{kg}$, four out of seven, and even after $20 \mathrm{mg} / \mathrm{kg}$, only three out of six showed decrements in the spontaneous activity of hippocampal neurons. The other cases showed either no changes or slight increases. Clearly, both in terms of magnitude of effect, and number of cases in which this decremental effect occurred, chlordiazepoxide and diazepam were more effective depressants than sodium pentobarbital, in this region of the central nervous system.

Meprobamate $(\mathrm{Mpb})$, like sodium pentobarbital, caused minor decreases in the rate of discharge of hippocampal cells. There was a lack of stability to these effects over time, and a dose of $100 \mathrm{mg} / \mathrm{kg}$ seemed to be more effective than a dose of $120 \mathrm{mg} / \mathrm{kg}$. The largest inhibition for the 15-90 min period after injection was only $30 \%$ (Table 1).

Control injections of physiological saline caused some fluctuations in the spontaneous activity of these cells, but there was no consistent or long-lasting effect over time. Control injections of polyethylene glycol 400 in seven subjects caused small but consistent increases. These were accompanied by hyperactivity and restlessness, sometimes lasting the length of the test period.

These four compounds differed also in terms of onset and duration of effects. Chlordiazepoxide and diazepam were effective depressants $15 \mathrm{~min}$ after treatment, and continued to be so during the complete $90 \mathrm{~min}$ test period without dramatic changes in the magnitude of the inhibition over time. Sudium pentobarbital had very little effect 15 min after injection; the largest decreases appeared $90 \mathrm{~min}$ after injection (Table 1). This difference is particularly noticeable in the case of chlordiazepoxide and meprobamate; the effect of chlordiazepoxide was beginning to wear off $90 \mathrm{~min}$ after injection whereas that of meprobamate, at $80 \mathrm{mg} / \mathrm{kg}$, was largest only 90 min after medication (Table 1).

When the effects of low doses of these four compounds were compared, diazepam and chlordiazepoxide appeared to be slightly more effective than the other two compounds in reducing neural activity, but at high doses the differences were striking (Fig. 2). Chlordiazepoxide and diazepam caused large decrements; sodium pentobarbital and meprobamate had little effect.

The data obtained with these four compounds suggest that hippocampal neurons were considerably more depressed after chlordiazepoxide and diazepam injections than they were after sodium pentobarbital and meprobamate.

\section{Effects in the pre-optic area}

Of the compounds tested, chlordiazepoxide and meprobamate were the most effective depressants of the spontaneous activity of cells in this region (Table 2). In the case of chlordiazepoxide, mean reduction from control rates before injection were $14 \%$ at the lowest dose, and between 30 and $50 \%$ at the higher doses. Similarly, depression was in the same range 
A

$\%$ OF NUMBER OF

SPIKES BEFORE INJECTION

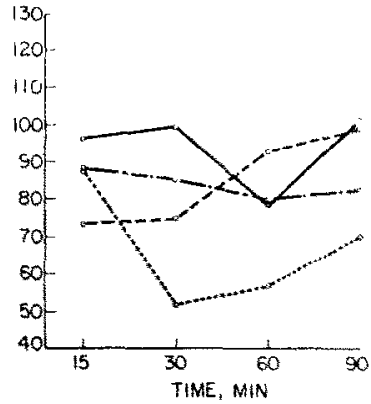

B

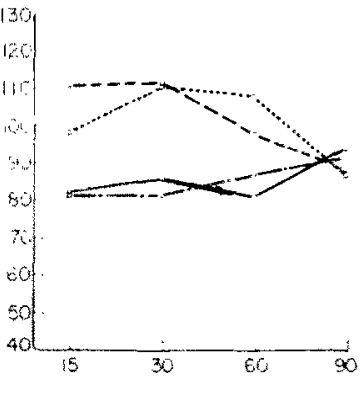

C

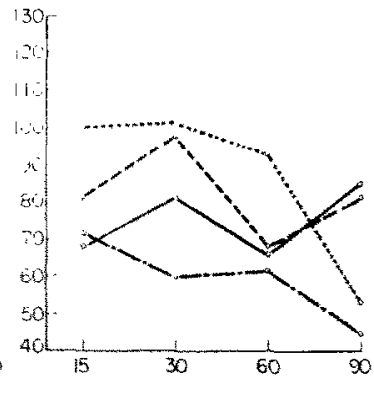

Frg. 2. Effects over time of low doses of chlordiazepoxide, sodium pentobarbital, meprobamate, and diazepam on the firing patterns of units in the reticular area of the midbrain, the pre-optic area, and the hippocampus. All drugs were given i.p. at a dose of $5 \mathrm{mg} / \mathrm{kg}$ except meprobamate which was injected at a dose of $80 \mathrm{mg} / \mathrm{kg}$. Number of spikes after medication expressed as percent of control. Each point is mean measurement of at least five separate experiments (Tables 1,2,3). Control values were obtained over a $90 \mathrm{~min}$ period before medication during which fifteen samples of spontaneous activity of the units in these regions of the brain were photographed at various intervals. See text for further detail. A: Effects of drugs on units in reticular area of midbrain. B: Effects in pre-optic area. $\mathrm{C}$ : Effects in hippocampus.

- chlordiazepoxide $5 \mathrm{mg} / \mathrm{kg} ; \ldots . .$. , sodium pentobarbital $5 \mathrm{mg} / \mathrm{kg} ; . . .$. , meprobamate $80 \mathrm{mg} / \mathrm{kg} ;-\cdots \cdot \cdots$, diazepam $5 \mathrm{mg} / \mathrm{kg}$

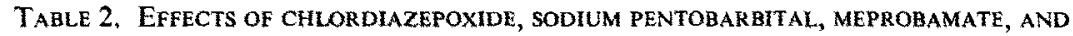
DIAZEPAM ON SPONTANEOUS FIRING OF NEURONS IN THE PREOPTIC AREA

\begin{tabular}{|c|c|c|c|c|c|c|c|c|}
\hline \multirow[b]{2}{*}{ Drug } & \multirow{2}{*}{$\underset{(\mathrm{mg} / \mathrm{kg})}{\text { Dose }}$} & \multirow[b]{2}{*}{$N$} & \multicolumn{4}{|c|}{ Mean percentage at time $(\mathrm{min})$ after injection } & \multirow{2}{*}{$\begin{array}{c}\text { Mean } \\
(15-90)\end{array}$} & \multirow{2}{*}{$\begin{array}{l}\text { S.D. } \\
( \pm)\end{array}$} \\
\hline & & & 15 & 30 & 60 & 90 & & \\
\hline Chlordiazepoxide & $\begin{array}{r}5 \\
10 \\
20 \\
40\end{array}$ & $\begin{array}{r}11 \\
8 \\
9 \\
5\end{array}$ & $\begin{array}{l}83 \\
72 \\
56 \\
69\end{array}$ & $\begin{array}{l}86 \\
82 \\
52 \\
57\end{array}$ & $\begin{array}{l}82 \\
83 \\
47 \\
60\end{array}$ & $\begin{array}{l}94 \\
72 \\
47 \\
69\end{array}$ & $\begin{array}{l}86 \\
77 \dagger \\
50 \dagger \\
64 \dagger\end{array}$ & $\begin{array}{l}28 \\
25 \\
17 \\
22\end{array}$ \\
\hline Na pentobarbital & $\begin{array}{r}5 \\
10 \\
20\end{array}$ & $\begin{array}{l}6 \\
7 \\
6\end{array}$ & $\begin{array}{r}111 \\
78 \\
89\end{array}$ & $\begin{array}{r}112 \\
81 \\
73\end{array}$ & $\begin{array}{l}98 \\
82 \\
78\end{array}$ & $\begin{array}{l}89 \\
83 \\
86\end{array}$ & $\begin{array}{c}102 \\
81+ \\
81 \dagger\end{array}$ & $\begin{array}{l}16 \\
26 \\
29\end{array}$ \\
\hline Meprobamate & $\begin{array}{r}80 \\
100 \\
120\end{array}$ & $\begin{array}{l}6 \\
5 \\
6\end{array}$ & $\begin{array}{l}99 \\
95 \\
73\end{array}$ & $\begin{array}{r}112 \\
70 \\
76\end{array}$ & $\begin{array}{r}109 \\
65 \\
45\end{array}$ & $\begin{array}{l}88 \\
77 \\
42\end{array}$ & $\begin{array}{c}102 \\
77 \\
59 \dagger\end{array}$ & $\begin{array}{l}34 \\
25 \\
20\end{array}$ \\
\hline Diazepam & $\begin{array}{r}5 \\
10 \\
20\end{array}$ & $\begin{array}{l}7 \\
5 \\
8\end{array}$ & $\begin{array}{l}83 \\
81 \\
87\end{array}$ & $\begin{array}{l}83 \\
72 \\
95\end{array}$ & $\begin{array}{l}88 \\
77 \\
91\end{array}$ & $\begin{array}{l}93 \\
81 \\
98\end{array}$ & $\begin{array}{l}86 \\
78 \\
93\end{array}$ & $\begin{array}{l}29 \\
24 \\
29\end{array}$ \\
\hline Glycol & & 7 & 118 & 114 & 102 & 100 & 107 & 29 \\
\hline $\mathrm{NaCl}$ & $9 \%$ & 7 & 95 & 110 & 138 & 117 & 115 & 18 \\
\hline
\end{tabular}

$* P=0.05 ; \uparrow P=0.01 ; \ddagger P=0.001$.

Each score was obtained by calculating the mean number of spikes in three $200 \mathrm{msec}$ periods, at various intervals after drug administration. Results reported as percentages of control values (see text). 
when compared to rates in subjects injected with an equal volume of physiological saline. Chlordiazepoxide was thus an effective depressant of neural activity, although at the lower doses there were cases in which this effect was not in evidence. For example, at a dose of $5 \mathrm{mg} / \mathrm{kg}$ only five out of eleven cases showed decreases in firing of pre-optic neurons; after $10 \mathrm{mg} / \mathrm{kg}$, five out of eight cases; and at higher doses, all subjects showed such inhibition. At the lowest dose, meprobamate had no effect; but at doses of $100 \mathrm{mg} / \mathrm{kg}$ and $120 \mathrm{mg} / \mathrm{kg}$, the decreases were between 25 and $40 \%$. At a dose of $80 \mathrm{mg} / \mathrm{kg}$, meprobamate decreased the spontaneous activity of pre-optic cells in only two out of six subjects, but at a dose of $100 \mathrm{mg} / \mathrm{kg}$, such decrease occurred in five out of five subjects, and at a dose of $120 \mathrm{mg} / \mathrm{kg}$, in six out of six subjects.

Although chlordiazepoxide and meprobamate were effective depressants of this brain region, they were not as effective at the lowest dose as on hippocampal neurons. Sodium pentobarbital had no effect at the low dose of $5 \mathrm{mg} / \mathrm{kg}$, but depressed activity by $20 \%$ at doses of 10 and $20 \mathrm{mg} / \mathrm{kg}$, although less so than either chlordiazepoxide or meprobamate (Table 2, mean 15-90 min period).

Diazepam had some depressant effects at doses of 5 and $10 \mathrm{mg} / \mathrm{kg}$ but these were not large and at a higher dose this effect was no longer evident.
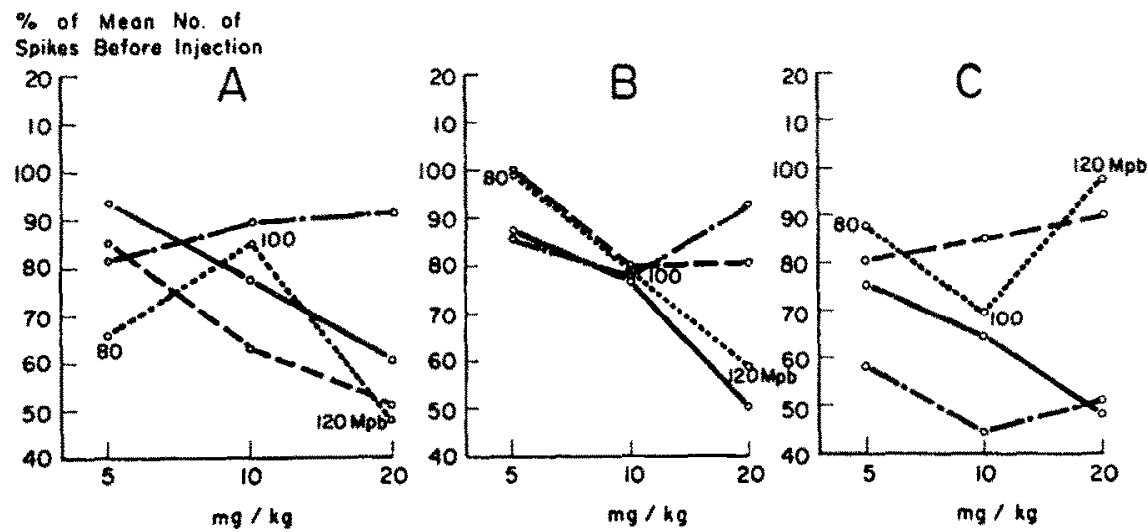

Fig. 3. Action of different doses of chlordiazepoxide, sodium pentobarbital, meprobamate, and diazepam on spontaneous firing of neurons in midbrain reticular area, pre-optic area, and hippocampus. A: Effects in reticular area of the midbrain. B: Effects in the pre-optic region. $\mathrm{C}$ : Effects in the hippocampus. Ordinate: total number of spikes recorded in consecutive $200 \mathrm{msec}$ periods during the 15-90 min interval after drug injection expressed as percentage of control values (see text). The position of each point was obtained by calculating the mean of measurements in at least five records, often more, (see Tables 1,2 and 3) obtained in separate experiments.

chlordiazepoxide; ....... sodium pentobarbital: ........, diazepam; ......, meprobamate $(\mathrm{Mpb})$.

All compounds, except diazepam, showed a dose-response relationship; chlordiazepoxide was more depressing at the higher doses than at a dose of $5 \mathrm{mg} / \mathrm{kg}$ (Fig. 3) but there was little difference between the effects of 20 and $40 \mathrm{mg} / \mathrm{kg}$. The largest differences occurred between 10 and $20 \mathrm{mg} / \mathrm{kg}$ when decreases progressed from $25 \%$ to $50 \%$ (Table 2 ). In the case of meprobamate, the largest dose was clearly the most potent depressant on these cells; whereas $100 \mathrm{mg} / \mathrm{kg}$ decreased spontaneous activity by $25 \%, 120 \mathrm{mg} / \mathrm{kg}$ decreased it by $40 \%$. 
When mean rates for the total 15-90 min period were compared, there was little difference in the magnitude of the inhibition betwcen doses of 10 and $20 \mathrm{mg} / \mathrm{kg}$ of sodium pentobarbital; on the other hand, when rates of discharge throughout the $90 \mathrm{~min}$ test period were compared, after 10 and $20 \mathrm{mg} / \mathrm{kg}$ of sodium pentobarbital, the effects were, in a majority of cases, larger at the higher dose (Table 2).

On these cells, glycol also caused minor increases in activity just as had been the case in hippocampus; control injections of physiological saline also tended to raise the rate of discharge on occasions.

When the time course of effects was compared, chlordiazepoxide, at most doses, had optimum effects either at 15 or $30 \mathrm{~min}$ after injection; only at a dose of $20 \mathrm{mg} / \mathrm{kg}$ was the depression large 15 min after treatment, and became still greater 30 and $60 \mathrm{~min}$ later. The depressant effects of chlordiazepoxide were in evidence early after treatment, as had been the case also in the hippocampus. In contrast, the maximum effect of meprobamate, at the two effective doses (100 and $120 \mathrm{mg} / \mathrm{kg}$ ), occurred 60 and 90 min after injection. Thus, in the pre-optic area there was a difference in magnitude and time course between effects on spontaneous activity obtained after chlordiazepoxide and meprobamate treatment. The slight depressant effects of sodium pentobarbital were apparent 15 and $30 \mathrm{~min}$ after injection, and recovery was apparent 60 and 90 min after treatment. Diazepam had minor and unstable effects which occurred 15 and $30 \mathrm{~min}$ after injection. Thus, only in the case of meprobamate was there both substantial depressant and delayed action on the spontaneous activity of pre-optic region neurons.

Comparing effects of all four compounds at low doses (Fig. 2) the data show that sodium pentobarbital and meprobamate caused slight facilitation, and only 90 min after medication was there depression in the $10 \%$ range; chlordiazepoxide and diazepam caused consistent though small decreases in the rate of firing of these cells, recovery appearing approximately $30 \mathrm{~min}$ after injection of these low dises.

Comparing effects at high doses (Fig. 4) it is apparent that chloriazepoxide and meprobamate had inhibitory effects in the same range only $90 \mathrm{~min}$ after injection, whereas earlier in time, chlordiazepoxide was effective but meprobamate caused only minor decrements. Sodium pentobarbital at $20 \mathrm{mg} / \mathrm{kg}$ was less effective than meprobamate at $120 \mathrm{mg} / \mathrm{kg}$ or chlordiazepoxide at $40 \mathrm{mg} / \mathrm{kg}$ except immediately after injection, when the data obtained with all compounds lacked stability because of handling and movement of the subject immediately thereafter.

To summarize effects on pre-optic cells, chlordiazepoxide seems to be the most effective depressant of spontaneous activity in the hippocampus, more so than sodium pentobarbital, even at the lowest dose used. This effect was rapid in onset and often lasted throughout the $90 \mathrm{~min}$ period after injection.

\section{Effects in midbrain tegmentum}

Meprobamate at every dose used depressed the spontaneous activity of neurons in this region of the brain. At $80 \mathrm{mg} / \mathrm{kg}$ the decrements ranged between 20 and $50 \%$; at higher doses, the inhibition became still more pronounced. The largest reductions occurred at a dose of $120 \mathrm{mg} / \mathrm{kg}, 30 \mathrm{~min}$ after injection, when spontaneous activity was reduced by $65 \%$ (Table 3 ). In contrast to the lack of stability of the meprobamate effects in hippocampus or pre-optic area, the reduction in activity after meprobamate on cells in this region showed consistent effects during the course of the test, and increasing doses caused larger depression. There were no cases of complete inhibition, even at the highest dose used. 


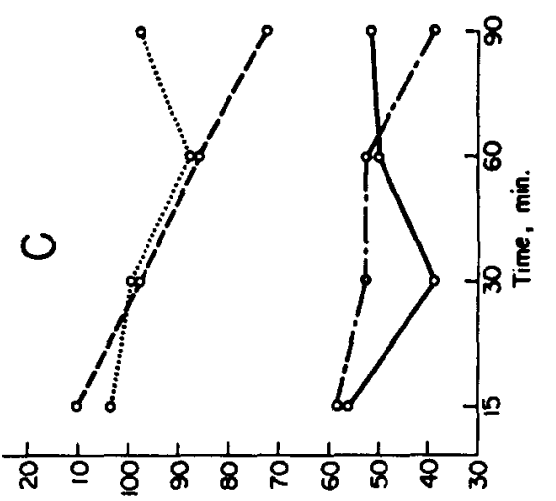

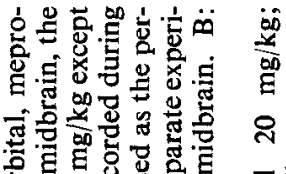

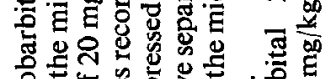

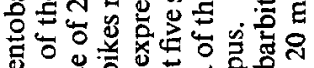

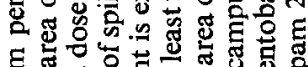

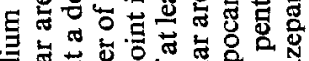

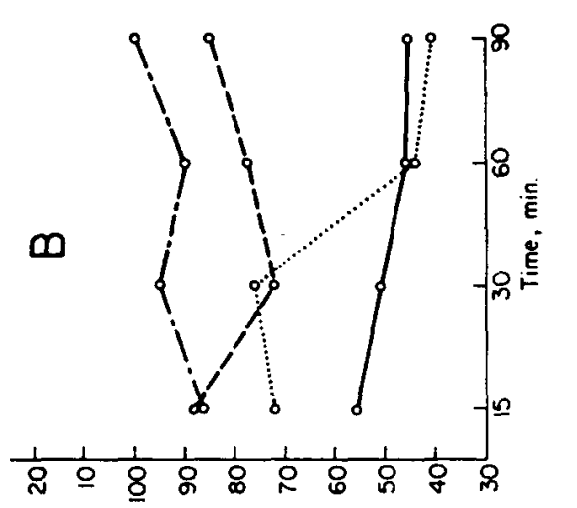

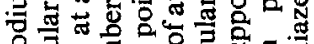

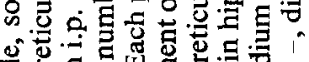

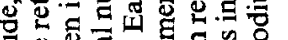
可焉

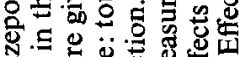

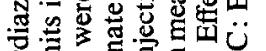

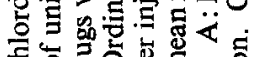

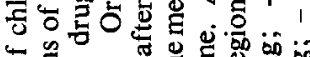

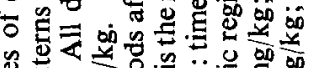
语语

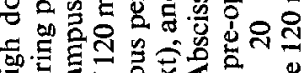

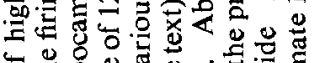

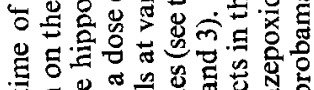

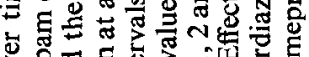

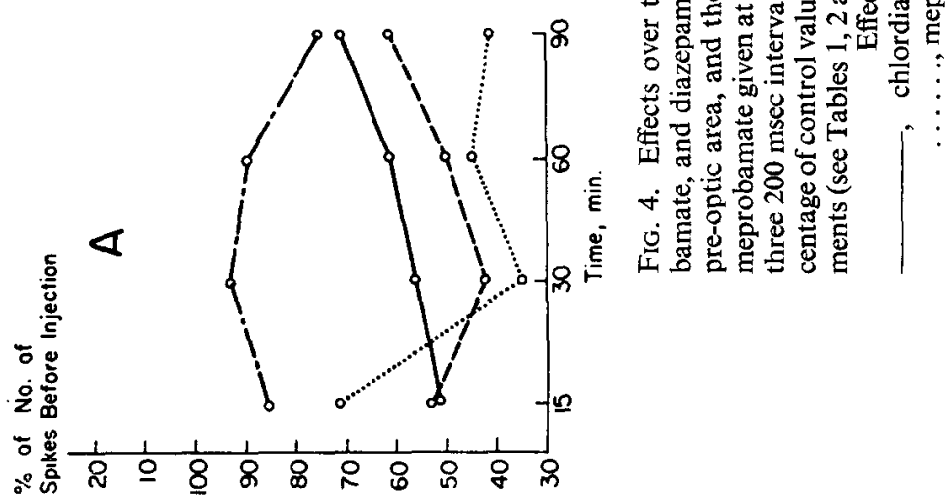


TABLE 3, EFFECTS OF ChLORDIAZEPOXIDE, SODIUM, PENTOBARBITAL MEPROBAMATE AND DIAZEPAM ON SPONTANEOUS FIRING OF NEURONS IN THE RETICULAR AREA OF THE MIDBRAIN

\begin{tabular}{|c|c|c|c|c|c|c|c|c|}
\hline \multirow[b]{2}{*}{ Drug } & \multirow{2}{*}{$\begin{array}{c}\text { Dose } \\
(\mathrm{mg} / \mathrm{kg})\end{array}$} & \multirow[b]{2}{*}{$N$} & \multicolumn{4}{|c|}{ Mean percentage at time (min) after injection } & \multirow{2}{*}{$\begin{array}{l}\text { Mean } \\
15-90\end{array}$} & \multirow{2}{*}{$\begin{array}{l}\text { S.D } \\
( \pm)\end{array}$} \\
\hline & & & 15 & 30 & 60 & 90 & & \\
\hline \multirow{4}{*}{ Chlordiazepoxide } & 5 & 8 & 97 & 99 & 78 & 102 & 94 & 31 \\
\hline & 10 & 7 & 70 & 53 & 98 & 92 & 78 & 27 \\
\hline & 20 & 5 & 52 & 56 & 62 & 71 & $60^{*}$ & 14 \\
\hline & 40 & 5 & 66 & 54 & 81 & 39 & $60^{*}$ & 21 \\
\hline \multirow[t]{3}{*}{$\mathrm{Na}$ pentobarbital } & 5 & 5 & 74 & 75 & 93 & 99 & 85 & 29 \\
\hline & 10 & 5 & 72 & 60 & 71 & 52 & 64 & 27 \\
\hline & 20 & 5 & 53 & 42 & 50 & 62 & $52^{*}$ & 25 \\
\hline \multirow[t]{3}{*}{ Meprobamate } & 80 & 8 & 88 & 52 & 56 & 70 & $67^{*}$ & 22 \\
\hline & 100 & 6 & 102 & 82 & 94 & 66 & 86 & 29 \\
\hline & 120 & 5 & 71 & 35 & 45 & 42 & $48^{*}$ & 23 \\
\hline \multirow[t]{3}{*}{ Diazepam } & 5 & 7 & 87 & 85 & 79 & 83 & 81 & 27 \\
\hline & 10 & 5 & 78 & 80 & 111 & 90 & 90 & 20 \\
\hline & 20 & 5 & 87 & 95 & 89 & 76 & 91 & 29 \\
\hline \multicolumn{2}{|l|}{ Glycol } & 5 & 141 & 111 & 133 & 165 & 137 & 53 \\
\hline \multicolumn{2}{|l|}{ Saline } & 5 & 121 & 110 & 99 & 123 & 114 & 36 \\
\hline
\end{tabular}

$* P=0.01$.

Each score was obtained by calculating the mean number of spikes in three $200 \mathrm{msec}$ periods, at various intervals after drug administration. Results reported as percentages of control values (see text).

Sodium pentobarbital was as effective as meprobamate as a depressant, but the onset of the effect appeared earlier, and at lower doses the effect was not as pronounced as it was at the lowest dose of meprobamate. For example, after $5 \mathrm{mg} / \mathrm{kg}$ sodium pentobarbital, only three out of five subjects showed reduction of neural aclivity of midbrain neurons, whereas after meprobamate at $80 \mathrm{mg} / \mathrm{kg}$, seven out of seven subjects showed such reduction. On the other hand, after sodium pentobarbital at $10 \mathrm{mg} / \mathrm{kg}$, five out of five subjects were depressed, and after a dose of $20 \mathrm{mg} / \mathrm{kg}$, also five out of five subjects. In other words, at the higher doses, sodium pentobarbital depressed neural activity in this region as much as meprobamate, although the latter did so even at the lowest dose used, $80 \mathrm{mg} / \mathrm{kg}$.

Chlordiazepoxide similarly reduced the activity of midbrain reticular cells (Table 3 ). However, at a dose of $5 \mathrm{mg} / \mathrm{kg}$, there was no effect except $60 \mathrm{~min}$ after injection, and this effect was not only transient, but also the reduction in activity was only $25 \%$ of control levels. At a dose of $10 \mathrm{mg} / \mathrm{kg}$, there was again depression of firing, $30 \% 15 \mathrm{~min}$ after injection, and $45 \% 30$ min after injection, but thereafter rates of discharge returned to premedication levels. At a dose of $20 \mathrm{mg} / \mathrm{kg}$, the rates of firing were depressed throughout the 90 min test period, but the largest decrements occurred 15 and 30 min after injection, and thereafter there was some recovery but it was not complete even 90 min after treatment. At a dose of $40 \mathrm{mg} / \mathrm{kg}$, there was not much difference in the magnitude of depression when compared to that which occurred after $20 \mathrm{mg} / \mathrm{kg}$. However, $90 \mathrm{~min}$ after injection, the decreases in discharge from pre-medication levels were more than $60 \%$ of control rates, and more than double that which occurred $90 \mathrm{~min}$ after injection of a dose of $20 \mathrm{mg} / \mathrm{kg}$ (Table 3 ).

Diazepam had minor effects on these midbrain cells. At lower doses there was some 
depression, and at the higher doses, there was some depression or facilitation, but the effect was not stable or significant.

When effects of low doses of all four compounds were compared (Fig. 2), meprobamate was the most effective depressant of neural activity in this region, although the effect was delayed until approximately $30 \mathrm{~min}$ after injection. Sodium pentobarbital was next; here the effect was optimum fifteen min after injection, and there was complete recovery 90 min after treatment. CDP was least effective, and diazepam appeared to have very small, insignificant effects.

Figure 4 shows the comparative data obtained with high doses. Meprobamate was still the most effective depressant of midbrain neurons, but optimum effect occurred only 30 min after injection and never reached more than $70 \%$. Sodium pentobarbital depressed initially more than meprobamate and more than chlordiazepoxide, but thereafter there was no recovery and little change in magnitude of the depression, except 90 min later when the rates were still $40 \%$ depressed. The maximum effect of chlordiazepoxide occurred $15 \mathrm{~min}$ after injection, depressing rates as much as did sodium pentobarbital, but less than meprobamate at this point in time. Subsequently, there was more recovery than occurred with sodium pentobarbital treatment, but rates were still $30 \%$ depressed 90 min after injection.

As had been the case in the other two areas in the brain, glycol facilitated somewhat neural activity of midbrain neurons, and saline caused minor fluctuations going either way, but in any event, of short duration.

On these neurons, therefore, meprobamate had marked effects both at high and low doses, although this effect had a delayed onset compared to the short acting, quick onset of chlordiazepoxide and sodium pentobarbital. On the other hand, at the higher doses, these last two compounds were almost as effective inhibitors of neural activity in this region as meprobamate, although there appeared to be recovery in the case of chlordiazepoxide and sodium pentobarbital, but not in the case of meprobamate.

\section{DISCUSSION}

It is sometimes said that microelectrode recordings have very limited value in pharmacological studies. The responses of a given neuron are usually recorded during short intervals only, whereas for drug studies, longer intervals are required. Further, it is possible to have entirely different effects to the same drug from neurons of a given nucleus, or neurons in the same anatomical area. In our studies, the use of ultra microelectrodes was not feasible, but the modification of small metal electrodes for permanent indwelling permitted the study of several action potentials from a given probe at once, and there could be several such probes in different brain regions of one subject. Not merely were spikes of constant amplitude held for several hours in the freely moving animal, but often when a subject was used again after an interval of several days in the home cage, spikes of the same amplitude were still observed from the same recording point.

It was therefore possible not only to analyze the effects of drugs on action potentials from a given brain point for several hours without loss of responses due to electrode movement, but also to repeat the test on the "same" responses after an interval of several days.

The data in this report support the view of differential reactions occurring sometimes to the same drug from adjacent neurons. There were cases when one spike recurred with the same frequency after medication while other action potentials of different amplitude recorded with the same probe were completely inhibited. However, in the present studies analysis 
of drug effects was not limited to the discharges of a single neuron but of a small population of neurons. Change of frequency in discharge of a single cell's firing was not analyzed. Instead it was the number of all different action potentials which met criteria for computation (amplitude relative to baseline-noise) during sampling intervals which determined finally whether a compound had an effect. Under these circumstances, it was quite possible that some cells were inhibited, others showed no change, and still others perhaps commenced to discharge after medication. And yet, it was found that the mean number of action potentials which could be computed over time after medication in a single animal, or in a group of subjects with probes in the same brain regions, showed remarkable stable effects after injection. The changes in number of spikes which could be counted over time after injection of some drugs were much larger than those which occurred either spontaneously over time, or after saline injections. Thus, although it may not be possible to predict the discharging pattern of two adjacent cells after the injection of a given compound, it seems that results obtained with the above technique vindicate this approach in pharmacological studies as one yielding direct evidence for site and mode of action.

There was a correlation between reduced discharges of neurons in all three brain regions and behavioral depression. At high doses, all subjects lay quietly in the test chambers, eyes often open, but with no apparent movements. At these high doses, rates of neural discharge were invariably much lower than before medication or medication at low doses. It has been reported a number of times that chlordiazepoxide, meprobamate, and the barbiturates have similar action at high doses. They induce EEG synchrony, reduce the amplitude of peripherally evoked responses, and raise the threshold for arousal due to electrical stimulation of the mesencephalic reticular formation (KILlAM, 1962; Domino, 1962; WHITE et al., 1965). Similarity of effects was also found at the neural level; at the highest doses, there was decrease of discharges in all three brain regions, although some differences were noted in time course of these effects. When glycol, the solvent of meprobamate and diazepam, was injected by itself, it was the only drug which induced motor activity and what seemed a rise in behavioral arousal after movements ceased. It was also the only compound which resulted in a slight, but reliable increase in the number of action potentials as compared to pre-medication rates. These results lend support to the view that the increase in firing rate in these three brain regions reflect the behavioral state of the animal. The more behaviorally active he appeared to the experimenter, the higher the number of action potentials which could be counted during the sampling intervals. Conversely, when the subject appeared sedated due to medication with high doses of sodium pentobarbital, meprobamate, or chlordiazepoxide, the fewer the number of responses which could be counted. The data obtained at high doses thus support the view that neural activity in the areas studied reflected the behavioral state of the animal in the sense that reduced wakefulness due to medication caused reduced neural activity. There was no evidence of facilitation in any of the three regions, with medication at high doses, which correlated with behavioral depression. These findings are particularly interesting in relation to data obtained by MiNK et al. (1967). In these studies, neural activity was studied in the same three brain regions during periods of "quiet awake" and "sleep with slow EEG waves" by means of the same general techniques but with computerized data analysis. As the subject passed from the waking to the sleeping state, neural discharges were invariably greatly reduced in the mesencephalic reticular formation, pre-optic arca, and hippocampus, although in the latter casc the changes werc less dramatic. Data obtained with sodium pentobarbital and the milder tranquilizers demonstrated that at the neural level, quiescence due to drugs involved a change in neural activity 
very similar to that which occurred as the animal moved from the normal quiet waking state to the "slow wave sleep" state, at least in the three regions in which electrodes were implanted.

It is interesting to note that our results support the notion of direct action of the barbiturates on the mesencephalic reticular formation. This region was significantly more depressed, even at low doses and earlier in time, than the pre-optic area and the hippocampus. Such effects were not unexpected since there has been mounting evidence pointing to the subcortical arousal mechanism as the site for direct action of anesthetics responsible for the behavioral effects produced by these drugs. Killam and Killam (1956), Bradley (1957), FRENCH et al. (1953), and others have demonstrated a depressant action in this region of the central nervous system due to barbiturates. Arousal produced by direct stimulation of the reticular formation was depressed after medication; conduction of nerve impulses in this brain region was blocked. There now appears to be general agreement that there are drug receptors in the mesencephalic reticular formation which are directly acted upon by barbiturates before action on other structures occurs, and that such action is largely responsible for the behavioral and EEG effects noted with these compounds (BRADLEY, 1957). Although evidence for this view has been obtained, sometimes indirectly, as in the case of cortical recording of EEG arousal, or inhibition of theta rhythm in hippocampus, it is thought that effects are produced by direct action on drug receptors in the reticular formation. Action on the other regions of the central nervous system are not precluded by this, although such action is not viewed as primarily responsible for the behavioral effects noted with the barbiturates.

These differential effects of sodium pentobarbital on the reticular formation find support in studies of behavior determined by electrical stimulation of small areas in hypothalamus or dorsal reticular formation. In the case where rats would press a pedal to admınister themselves an electrical shock to hypothalamus, sodium pentobarbital at a dose of $5 \mathrm{mg} / \mathrm{kg}$ would occasionally facilitate such behavior. On the other hand, at the same dose, pedal pressing to escape a shock administered to a discrete point in dorsal midbrain tegmentum would be depressed (M. Olds et al., 1964; M. Olds and J. Olds, 1965). It would seem therefore that at this low dose some type of behavior was facilitated while behavior dependent on the excitability of the dorsal mesencephalic reticular formation was depressed. Here then again, the mesencephalic reticular formation appears to be implicated directly in the mode of action of the barbiturates, and this action was noted at low doses, before depression of other regions was effected.

In addition to EEG and behavioral studies, the data obtained with microelectrodes provide additional evidence for the view that the barbiturates have direct and early action in the mesencephalic reticular formation. Neural activity was reduced in this region before depression of similar magnitude occurred in the pre-optic area or in hippocampus. The results obtained with sodium pentobarbital at low doses on action potentials in the mesencephalic reticular formation thus add to the already available evidence pointing to the mesencephalic reticular formation as the site of action of this compound and depression of activity as its mode of action.

The most interesting and least expected result was the selective inhibition in hippocampus after chlordiazepoxide and diazepam. It has been suggested that the action of these compounds is via limbic structures rather than arousal mechanisms (SCHALLEK et al., 1964); a similar claim has been made for meprobamate (KLETZIN and SWAN, 1959). There are differences, however, in effects at the behavioral level between meprobamate and the benzodiazepines (Liberson et al., 1963; Richelle et al., 1962; XHENSEval and Richelle, 1965; 
HeRnÁNDEZ-PÉon et al., 1964; M. E. Olds, 1966). Even at the neurophysiological level, it is not clear that the effects of the diazepines and meprobamate are similar. There are no reports suggesting increases in EEG frequency after meprobamate medication, whereas this appears to be the case with chlordiazepoxide injection (SCHALLEK et al., 1964; SCHALLEK and KUEHN, 1965). In studies of peripherally evoked responses from dorsal midbrain tegmentum of the rat, meprobamate at low doses increased the amplitude of the responses as did sodium pentobarbital, whereas chlordiazepoxide and diazepam decreased the size (M. OldS and BALDRIGHI, 1968). At high doses, the effects were the same. In other words, there are data suggesting different behavioral and neurophysiological effects of the benzodiazepines and meprobamate. The data obtained in the present studies on extracellular recordings of cells in hippocampus and two other brain regions suggest that the hippocampus was depressed by the diazepines at doses which leave the other two regions relatively unaffected, and that meprobamate and sodium pentobarbital did not have such action at low doses.

There are two points worthy of attention in connection with the findings of selective depression of hippocampus by the benzodiazepines. The first is that there is some evidence for this selective action in the work of Morillo (1962), who found that chlordiazepoxide and diazepam acted as powerful depressants at the amygdalo-hippocampal level. Responses recorded in hippocampus to single shocks administered in amygdala were depressed at doses which left the interhippocampal response and the cortical response to repetitive mesencephalic reticular formation shock unaffected. These findings give support to the likelihood of selective action of chlordiazepoxide and diazepam on hippocampal neurons and further suggest the hippocampus as the site for such drug receptors.

The second point relates to behavioral effects of chlordiazepoxide and diazepam on self-stimulation behavior elicited from administration of electrical shock to lateral hypothalamus. The surprising effect of the administration of the benzodiazepines at low doses was the facilitation of such behavior in a very large number of cases, whereas administration of meprobamate and sodium pentobarbital, even at very low doses, seldom caused increased responding. The interpretation of this behavioral effect was that the diazepines inhibit selectively an aversive system in the midbrain tegmentum. Slightly inconsistent with these results was the fact that chlordiazepoxide at $5 \mathrm{mg} / \mathrm{kg}$ (the facilitating dose) was not very effective in depressing escape behavior produced by electrical stimulation of dorsal midbrain tegmentum (the "aversive" system), whereas sodium pentobarbital and meprobamate appeared to be more effective than either of the former compounds, at comparable doses, in depressing such escape responding. The data obtained in the present studies together with other findings, suggesting the hippocampus as the site of action of benzodiazepines, lead to the conjecture that the facilitation obtained on hypothalamic self-stimulation also may be due to the selective depression of hippocampus. The possibility exists that the hippocampus and perhaps also the amygdala (if one takes account of the MoRILLo finding) normally exert an inhibitory action on the hypothalamus; and when such action is inhibited (by certain compounds and at doses which do not depress the mesencephalic reticular formation or the hypothalamus itself), there is a rise in self-stimulation behavior, or in behavior in general (HERNÁNDEZ-PF́n et al., 1964).

It must be noted that there was, on rare occasions, a facilitatory effect on self-stimulation behavior of sodium pentobarbital and meprobamate at low doses, but at a lower frequency than the similar effect with the benzodiazepines. It may be that in such individual cases, there was some depressant action of hippocampus but not of mesencephalic reticular formation or hypothalamus. However, these are theoretical possibilities at present. 
A final point worthy of note is the action of meprobamate on mesencephalic reticular formation and pre-optic area. These effects were similar in nature to those obtained with sodium pentobarbital except for two properties. The first is that whereas sodium pentobarbital had rapid action, there was delay in the onset of effects after meprobamate injection. The second is that the solvent of meprobamate was gylcol which reliably caused minor facilitation lasting after the $90 \mathrm{~min}$ test period, whereas the slight activity noted after saline was transient and random. Because of the motor activity often noted after meprobamate and glycol injections, the depressing effects in mesencephalic reticular formation and preoptic area were particularly striking. The effect of meprobamate on the mesencephalic reticular formation and the pre-optic area lend plausibility to the view that this compound effects some limbic region, but also to the view that its action is similar to that of sodium pentobarbital in selectively depressing the mesencephalic reticular formation.

Acknowledgement-The excellent technical assistance of Mrs. KathleEn KesLing, Mr. Guilio Baldrighi and Mrs. H. JEANE FreY are gratefully acknowledged.

\section{REFERENCES}

BRADleY, P. B. (1957). Microelectrode approach to the neuropharmacology of the reticular formation. Psychotropic Drugs (GaratTINI, S. and Ghetri, V., Editors), pp. 207-216. Elsevier, Amsterdam.

DE GRoOT, J. (1963). The Rat Forebrain in the Stereotaxic Courdinates. N. Hollandische Uitgevers Matatschappij, Amsterdam.

Domino, E. F. (1962). Sites of action of some CNS depressants. Ann. Rev. Pharmac. 2: 215-268.

French, J. D., Verzeano, M. and Magoun, H. W. (1953). Neural basis of anesthetic state. Archs Neurol. Psychiat. 69: 519-529.

GibBs, F. A. and GiBBs, E. L. (1962). Clinical and pharmacological correlates of fast activity in electroencephalography. J. Neuropsychiat. 3 (Suppl. 1.): S73-78.

Hernández-PÉon, R., Rojas-Ramirez, J. A. and O'FlaherTy, J. J. (1964). An experimental study of the anticonvulsive and relaxant actions of valium. Int. J. Neuropharmac. 3: 405-412.

KILLAM, E. K. and Kill.AM, K. F. (1956). A comparison of the effects of reserpine and chlorpromazine to those of barbiturates on central afferent systems in the cat. J. Pharmac. exp. Ther. 116: 35.

Killam, E. K. (1962). Drug action on the brain stem reticular formation. Pharmac. Rev. 14: 175-223.

KLETZIN, M. and SwaN, K. (1959). The effects of meprobamate and pentobarbital upon cortical and subcortical responses to auditory stimulation. J. Pharmac. exp. Ther. 125: 35-39.

Liberson, W. T., KAfKa, A., Schwartz, E. and Gagnon, V. (1963). Effects of chlordiazepoxide (librium) on fixated behavior in rats. Int. J. Neuropharmac. 2: 67-69.

Mink, W. D., Best, P. J. and OLds, J. (1967). Neurons in paradoxical sleep and motivated behavior. Science 158: $1335-1337$.

Morillo, A. (1962). Effects of benzodiazepines upon amygdala and hippocampus of the cat. Int. J. Neuropharmac. 1 : 353-359.

Olds, J. (1965). Operant conditioning of single unit responses. Excerpta Medica International Congress Series No. 87. Proc. XIII int. Cong. Physiological Sciences, Tokyo, pp. 372-380.

OLDS, J. (1967). The limbic system and behavioral reinforcement. Structure and Function of the Limbic System (Adey, W. and Tokizane, T., Editors), pp. 144-164. Elsevier, New York.

Olds, J., BeST, P. J. and Mink,W. D. (1967). Neuron correlates of motivational processes. Science 158: 533.

OLDS, M. E. (1966). Facilitatory action of diazepam and chlordiazepoxide on hypothalamic reward behavior. J. comp. physiol. Psychol. 62: 136.

OLDS, M. E. and BALDRIGHI, G. (1968). Effects of meprobamate, chlordiazepoxide, diazepam, and sodium pentobarbital on visually evoked responses in the tecto-tegmental area of the rat. Int.J. Neuropharmac. 7: 231-239.

Olds, M. E., Hogberg, D. and Olds, J. (1964). Tranquilizer action on the thalamic and midbrain escape behavior. Am.J. Physiol. 206: 515-520.

OLDS, M. E. and OLDS, J. (1965). Pharmacological patterns in subcortical and reinforcement behavior. Int. J. Neuropharmac. 2: 309-325.

Requin, S., LANOIR, J. and PLAS, R. (1963). Etude comparative des effets neurophysiologiques du Librium et du Valium. C.r. Séanc. Soc. Biol. 157: 2015-2019. 
Richelle, M., Xhenseval, B., Fontaine, O. and Thone, L. (1962). Action of chlordiazepoxide on two types of temporal conditioning in rats. Int. J. Neuropharmac. 1: 381-391.

Roldan, E. and Escobar, A. (1961). Control of convulsive activity and the effects on afferent transmission produced by methaminodiazepoxide: Experimental study in the cat. Bol. Inst. Estud. Med. Biol., Mexico, 19: $125-153$.

Schallek, W., Zanbransky, F. and Kuehn, A. (1964). Effects of benzodiazepines on the central nervous system of cat. Archs int. Pharmacodyn. 149: 467-483.

SchALLEK, W. and KuEHN, A. (1965). Effects of benzodiazepines on spontaneous EEG and arousal responses of cats. Progress in Brain Research, Vol. 18, pp. 231-238. Elsevier, New York.

SIEGEL, S. (1956). Nonparametric Statistics for the Behavioral Sciences. McGraw-Hill, New York.

Special report psychopharmacology program of the National Institute of Mental Health (1965). Psychopharmacology Service Center Bulletin. U.S. Department of Health, Education and Welfare, Washington, D.C.

Strumwasser, F. (1958). Long-term recording from single neurons in brain of unrestricted mammals. Science 127: 469-470.

White, R. P., Sewell, H. H., Jr. and Rudolph, A. S. (1965). Drug-induced dissociation between evoked reticular potentials and the EEG. Electroenceph. clin. Neurophysiol. 19: 16-24.

Winfield, D. L. and Aivazian, G. H. (1961). Librium therapy and electroencephalographic correlates. J. nerv. men. Dis. 133: 240-246.

Xhenseval, B. and Richelle, M. (1965). Behavioral effects of a long-term treatment with meprobamate in cats. Int. J. Neuropharmac. $4: 1-12$. 